\title{
Innovations
}

\section{Old age psychiatry and mental handicap}

\author{
N. Pearson, Consultant Psychiatrist; and J. Smithies, Consultant Psychiatrist, \\ Alderney Hospital, Poole BH12 4NB
}

We report on the first two years of a novel, controversial approach in East Dorset where consultants in old age psychiatry have taken on the consultant responsibility for patients who have mental handicap. We discuss our experience as it may be of interest to others where there are problems recruiting consultants in the psychiatry of mental handicap.

\section{Background}

In East Dorset, we have been fortunate over many years in having an innovative, forward looking, and supportive management team which has remained remarkably constant. We have faced successfully the closure of Coldharbour Hospital in Sherborne, our local large mental handicap hospital, and the rehousing of the patients in locally based hospital units. This was also difficult because Coldharbour is in West Dorset (at the time of writing managed by a separate health authority) at least $\mathbf{4 0}$ miles from the catchment area population. The resident population of East Dorset is some 450,000 people, many living in the conurbations of Poole and Bournemouth.

The original consultant provision was one wholetime consultant in mental handicap for the whole district, two whole-time old age psychiatrists for the western half of the district and one and a half old age psychiatrists for the eastern half of the health district. One of the authors (Joan Smithies) was one of the two consultants in old age psychiatry in the western half of the health district.

It was decided in March 1988 that Joan Smithies would take up responsibility in mental handicap as well as old age psychiatry. Initially this was seen as a temporary measure to provide some input into mental handicap as there was a consultant vacancy at that time which was proving difficult to fill. Despite having no experience in mental handicap, Joan Smithies was able to provide a satisfactory level of consultant supervision in mental handicap. She very much enjoyed the work and felt that it married well with her old age psychiatry work. The total workload was, however, excessive as she was doing two full-time consultant jobs. At that time Nicholas Pearson was Dr Smithies' senior registrar in old age psychiatry. An old age psychiatry post was advertised to relieve Joan Smithies of some of her clinical workload. Nicholas Pearson was successful in obtaining this post, but he had become interested in the idea of a split post between old age psychiatry and mental handicap. Accordingly, after his appointment, the two authors agreed to split the old age psychiatry and mental handicap workloads so that they were each doing a half-and-half job.

\section{How has it worked?}

Although there have been no formal studies, the evidence suggests that the service is running smoothly. The in-patients in the locally based hospital units (LBHUs) have improved in many areas of their lives, due to the effectiveness of the multi-disciplinary team working in conjunction with the two consultants. Mental illness and behavioural disorders have been managed energetically. There are regular, consultant led case conferences on all LBHU patients and there is a strong emphasis on carer and patient participation and involvement in care plans. There is a firm belief in maximising an individual's potential and there are opportunities for a range of activities and pursuits. "Targets" set for the contract with the district health authority have (so far!) been met in every respect.

\section{What are the advantages in a consultant working in both old age psychiatry and mental handicaps?}

(a) Many of the standards aimed at for old age psychiatry patients are similar for mental handicap. For example, patients with dementia require a longterm approach where disability is minimised and abilities encouraged, i.e. the principles of rehabilitation. We are not usually aiming at a "cure".

Change may occur slowly in dementia and we therefore operate over a long time-scale. We try to reduce the impact of deterioration in mental handicap, accelerate the process of aquisition of new skills, and develop effective strategies for reducing problem behaviours. 
(b) Carers are seen as paramount in both services. They may act as advocates, particularly when the patient is incapable of giving valid consent and supporting them through difficult times is crucial. Both services work as flexibly as possible to try and meet carers' (as well as patients') needs.

(c) The structure of the two services is similar in some respects, e.g. in-patient, out-patient, respite care and continuing care are common to both.

(d) "Cross-fertilisation" of ideas occurs from one side to the other, e.g. the setting up of regular case conferences (as in mental handicap) for patients with severe dementia, resident in long stay hospital beds. The application of knowledge of elderly patients with dementia to those mental handicapped people with Down's syndrome who develop Alzheimer's disease is another example.

(e) In both of these sub-specialities there is a need to be skilled in the psychiatry of the organically impaired.

(f) A joint service of this nature is ideally placed to meet the needs of the increasing numbers of the elderly mentally handicapped.

(g) There is an Assistant General Manager who manages both ESMI and Mental Handicap Services. Close co-operation between consultants and managers has led to developments and improvement in the quality of services. Management have found the present arrangements very satisfactory.

(h) The work is more stimulating and interesting with diversity of patients.

(i) Two consultants sharing the work is better than one full-time as there is an avoidance of professional isolation - we can turn to each other for discussion, advice, and planning the service. We can cover each other for leave. We also have close links with the adult psychiatrists through our old age psychiatry workload which benefits patients with mental handicap, particularly those who may have mild or borderline handicaps and who become mentally ill.

\section{Disadvantages}

(a) Being involved in two community based services involves a lot of travelling. "Time management" is vital.

(b) There can be duplication of work across two clinical management teams. This has been beneficial on one or two occasions, e.g. when the Director of Finance was explaining the position of the community health service unit as a whole, it was quite useful to hear it a second time to clarify finer points of financial strategy!

(c) We are both fully trained as old age psychiatrists and have a partial training in mental handicap. This has not had any great impact on a clinical level. It has been important to attend conferences (what few there are in mental handicap) where possible, and further develop our knowledge. This, of course, should apply in any case for all doctors at whatever level.

It is reassuring that basic training in psychiatric assessment, diagnosis and clinical management has stood us in good stead. Further training in old age psychiatry has been of direct benefit to mental handicap as expounded earlier (i.e. communality of approach). Higher training in "rehabilitation" in adult psychiatry, in our view, would also serve a potential mental handicap consultant well.

Ideally, a senior registrar would spend time in both specialities, but this is not possible on most senior registrar rotations.

\section{Conclusion}

We have found the combination of duties rewarding. We have been able to provide consultant leadership across two clinical management teams and to forward in our district the cause of the elderly mentally ill and the mentally handicapped who become our patients. This has been possible with the support of our consultant colleagues and our imaginative, forward-looking management team.

We hope the College will adopt a more flexible role over training and consultants advisory appointments committees be responsive to individual districts' requirements, particularly where innovation is suggested. In our view, the calibre of the "team", particularly the consultants in that team, and their vision for the future service, is more important than sectarian interests of any particular sub-speciality of the Royal College of Psychiatrists.

\section{Comment from $\mathrm{Dr}$ Y. Wiley, Chairman, Section for the Psychiatry of Old Age}

The President of the College sent me this interesting report for comment.

I am, of course, aware of the problems there have been in Wessex in staffing consultant posts in the psychiatry of mental handicap. I am also aware of how hard you have worked in providing a service and how this has been valued locally. However, I should point out that the Section for the Psychiatry of Mental Handicap is the longest established Section in the College and has worked very hard at establishing good training schemes throughout the country for SRs in the specialty. I think it unlikely, therefore, for psychiatrists to be trained adequately both in old age psychiatry and in mental handicap although there are undoubtedly many common threads of approach of service delivery.

I am sure we can learn from each other and possibly some joint academic meetings would be of interest to both sections. 